\title{
Effects of New Grocery Store Development on Inner-City Neighborhood Residential Prices
}

\section{Belkis Cerrato Caceres and Jacqueline Geoghegan}

\begin{abstract}
A difference-in-differences approach is used to measure the impact of new innercity grocery store developments on residential housing values in Worcester, Massachusetts. Using geocoded housing sales from 1988-2011, we develop a hedonic model, exploiting temporal and spatial discontinuities, to identify the effect of 12 new grocery stores on neighborhood housing prices. Results suggest these new stores were associated with an increase in sale prices of nearby homes, and these results could help inform current policies related to urban food deserts, in that new grocery stores have the potential to improve neighborhood wealth as well as health.
\end{abstract}

Key words: difference-in-differences, grocery stores, hedonic models

The burgeoning obesity epidemic in the United States (Nguyen and El-Serag 2010, Flegal et al. 2012), with large disparities among different population groups along ethnicity and socioeconomic lines (Wang and Beydoun 2007), has highlighted the need for access to affordable healthy food throughout the United States. The presence of strong residential segregation in housing markets among these socioeconomic groups may affect the local food environment, which potentially can be a factor in leading to these negative health outcomes for disadvantaged groups. Geographic areas lacking in affordable healthy food have been termed food deserts, and a growing research literature from many academic disciplines has demonstrated that these food deserts are more likely to occur in poorer neighborhoods (Powell et al. 2007, Chen et al. 2010, Walker, Keane, and Burke 2010). These geographic regions are more likely to have more convenience stores and fast food outlets than grocery stores, resulting in less healthy food consumption and worse health outcomes for their residents (Brown et al. 2008, Galvez

Belkis Cerrato Caceres is an Assistant Professor of Economics at Edgewood College. Jacqueline Geoghegan is a Professor of Economics at Clark University. Correspondence: Belkis Cerrato Caceres - Department of Social Science, Edgewood College - 1000 Edgewood College Dr = Madison, WI 53711 - Phone 508.793.7709 - Email bcerrato@edgewood.edu

The authors would like to thank John Brown, Wayne Gray and Wang Jin for advice and suggestions, as well as two anonymous reviewers for very helpful comments. In addition, research support for this project from the Mosakowski Institute for Public Enterprise at Clark University is gratefully acknowledged.

Agricultural and Resource Economics Review 46/1 (April 2017) 87-102

(C) The Author(s) 2017. This is an Open Access article, distributed under the terms of the Creative

Commons Attribution licence (http://creativecommons.org/licenses/by/4.0/), which permits unrestricted re-use, distribution, and reproduction in any medium, provided the original work is 
et al. 2009). Other studies have demonstrated the positive relationship between access to grocery stores offering a greater variety of healthy food at lower prices and improved health outcomes for neighborhood residents (Morland et al. 2002, Zenk et al. 2005, Moore and Roux 2006, Auld and Powell 2008, Krukowski et al. 2010, Yan, Bastian, and Griffin 2015).

These linkages between food deserts and poor health outcomes for their residents has led the U.S. Federal Government to establish the Healthy Food Financing Initiative (HFFI), a partnership among the Treasury Department, Health and Human Services, and the U.S. Department of Agriculture (Holzman 2010 ), with over $\$ 140$ million in grants distributed since 2011, funding a range of projects to increase access to healthy foods (Healthy Food Access Portal 2015) and with continued support of $\$ 125$ million authorized in the 2014 Farm Bill (USDA 2014). In addition, a portion of Michelle Obama's "Let's Move!" campaign has worked with grocery chains including SUPERVALU, Walgreens, Walmart and regional retailers such as California Fresh Works Fund and Brown's Super Store (The White House Office of the First Lady, 2011) that have pledged to open more stores in underserved areas. However, it is too early to tell if either of these two new initiatives have had an impact on the health outcomes of residents in these communities (Cummins, Flint, and Matthews 2014).

With this new policy focus on expanding grocery stores in food deserts, we investigate a related but under-researched question: what are the effects of new urban grocery stores on residential property values? As discussed above, many of these geographic areas often are home to lower-income residents; any changes in their housing prices may affect their financial health as well. We use an interesting case study of Worcester Massachusetts, to help shed light on this question. Worcester is the second largest city in New England, with a population of approximately 181,000 in 2010, located in central Massachusetts, about 50 miles west of Boston. While Worcester has a larger minority population than the state as a whole (36 vs. 22 percent) and lower income $(\$ 43,492$ in 2012 , about two thirds of the state median household income), which are the usual sociodemographic characteristics of residents in food deserts, between 1988 and 2012, 12 new grocery stores opened in the city, tripling the number of grocery stores in the city, during a time frame when overall population increased by approximately 7 percent and new home construction was at the lowest level of the past 60 years (Executive Office of Economic Development, City of Worcester, MA, 2012). Strikingly, these new grocery store openings occurred before any of the recent policy initiatives in Massachusetts, such as the passage in 2014 of the Massachusetts Food Trust Program to authorize \$2 million for food initiatives in low- and moderate-income communities. Therefore, we use the experience of Worcester to help inform policymakers of these potentially unintended consequences of new grocery store developments on neighborhood financial health, for proposals such as the HFFI. 


\section{Research Questions and Empirical Strategy}

The past half century of economic research on the capitalization of residential housing prices of different neighborhood amenities and disamenities associated with nearby land uses and access to features of the landscape demonstrates that homebuyers have preferences over these features. Most of these analyses use a hedonic pricing approach to test hypotheses concerning the sign and size of these effects. Hedonic models are reduced-form statistical models used to trace the locus of equilibrium transaction prices as a function of the characteristics of the real estate transacted. These models assume that a residential property is a heterogeneous good, made up of a bundle of characteristics. Each characteristic of the parcel, including surrounding land uses and access to landscape features, contributes to the sales price of the property. Examples of applications of hedonic models to value different amenities and disamentities include: clean air (Smith and Huang 1993); clean water (Leggett and Bockstael 2000); open space (Geoghegan 2002); Superfund sites (Kiel and Williams 2007); airport noise (Pope 2008); transportation access (Bowes and Ihlanfeldt 2001); among many others (for an overview of hedonic property models, see Palmquist 2005).

Early examples that explicitly try to measure the effect of commercial land uses on neighboring housing prices include Li and Brown (1980) and Song and Knapp (2004). In two recent applications (Johnson et al. 2015, Pope and Pope 2015), researchers investigate the effect of large "big box" retail establishments, such as Target and Walmart on nearby residential land markets. While Walmart is currently the largest grocery retailer in United States and as a result can have an impact on local food prices, (Ellickson and Grieco 2013), these stores also are much larger than a "traditional" grocery store, sell many other household items, and do not often open in urban core neighborhoods. Therefore the results from these studies may not carry over to our research question. However, the key motivations and empirical strategy put forth by Pope and Pope (2015) are relevant for us. They argue that a new Walmart could be viewed an amenity, valued for increased ease of access, or as a disamenity, due to congestion and other negative externalities. We make a similar argument for the impact of a new grocery store on nearby residential values as well, specifically that the grocery store is a disamenity for properties that are very close, as a result of congestion and noise externalities, while the grocery store becomes an amenity at a slightly further distance, because of easier access, but that the effect decays as the distance between the house and the grocery store increases. However, it is an empirical question of the relevant distances to have a measureable impact, and therefore we use a number of different distances to test this effect in our empirical specification.

Pope and Pope (2015) also discuss the limitations of the early hedonic models that investigated issues related to the impact on housing prices of different externalities and accessibility features of the landscape. First, these models used a cross-sectional approach to estimate the effect of the feature in 
question; therefore, omitted variable bias could affect the estimated implicit prices if other features of the landscape also influence residential land prices but are not included in the model. Second, by ignoring the endogenous nature of the locational choice of a new store, a traditional cross-sectional approach could also result in biased estimation of implicit prices. Instead, Pope and Pope advocate for the use of new methods in quasiexperimental design that make use of discontinuities in time and/or space to help clearly identify and estimate the implicit prices of the characteristics of interest (for an overview of this approach, see Parmeter and Pope 2013; for an application of this approach to housing markets in Worcester, see Brown and Geoghegan 2011). Given information on both the timing and location of new Walmart stores opening, they develop a difference-in-differences approach to compare residential sale prices before and after the construction of a Walmart store for residential properties located near a new store (the treatment group) to residential properties located further away from a new store (the control group). The key feature of this empirical strategy is that it can avoid the potential endogeneity of both the location and timing decision of the opening of these new stores.

Given similar concerns for the endogeneity of the timing and location of new grocery store openings in Worcester, we take a parallel difference-in-differences approach as well, using temporal and spatial discontinuities to address the potential endogeneity issue. As Pope and Pope argue, by including spatial fixed effects in the empirical specification and comparing residential sales before and after the opening of each new grocery store, the omitted variables that could potentially bias a traditional hedonic approach that do not change over time are differenced away. However, for this approach to be valid, the assumption is that the time trends in housing prices would be the same in the treatment and control groups would have been the same without the opening of the new store (Pope and Pope, 2015). Given that our analysis focuses on a single city, coupled with the spatial specificity and disaggregation of our data, we believe this is a reasonable assumption. In addition, we include falsification tests and time trend analysis below to further justify this assumption.

Therefore, similar to Pope and Pope, we use residential properties within an 800-meter (approximately one-half mile) radius of the grocery store as the treatment group, and properties located more than 800 meters away as the control, with interactions with an indicator variable for properties that sold after the new store opening ${ }^{1}$. Our empirical specification is:

$$
\ln \left(\text { Price }_{i j y}\right)=\beta_{j y}+\alpha \boldsymbol{X}_{i}+\gamma \boldsymbol{Y}_{i}+\theta_{1}^{d} \boldsymbol{D}_{i j}^{d}+\theta_{2}^{d} \boldsymbol{D}_{i j}^{d} \text { Post }_{i y}+\varepsilon_{i j y}
$$

The log of a sales price of home $i$ is a function of a grocery store $j$ by year $y$; a specific store and year effect $\left(\beta_{j y}\right)$; an indicator variable for the year of

1 USDA (2009) establishes that a grocery store's walkability access is high if the nearest grocery store is within 0.5 miles, approximately 800 meters, walking distance. 
residential sale $\left(Y_{i}\right)$; observable individual house characteristics as well as neighborhood characteristics $\left(X_{i}\right)$; indicator variables, $\left(D_{i j}^{d}\right)$ for sales within a prespecified distance $(d)$ from the grocery store regardless of whether the grocery store has been established or not (where the distance varies as described below in the data description); interactions of each of these spatial indicators with an indicator (Post $t_{i y}$ ) for if the sale occurred after the opening of the grocery store, and an error term $\left(\varepsilon_{i j y}\right)$.

The estimated parameters of the model include: $\alpha$ is a vector of coefficients for the effects of various housing and neighborhood characteristics; $\gamma$ captures annual changes in the real estate market that could result from macroeconomic fluctuations; $\theta_{1}$ estimates the fixed effect of being located within distance $d$ from a grocery store; and $\theta_{2}$ measures the price effect of being located within distance $d$ from a grocery store after the date of opening of the grocery store. Statistical significance of $\theta_{2}$ implies that grocery store openings have an effect on a particular neighborhood's real estate market. In addition, as discussed above, we hypothesize that the coefficient will be negative for properties located adjacent to, or in close proximity to, a grocery store, because of congestion and other negative externalities, but positive for properties located somewhat further away, due to the positive effect of accessibility, but that the positive impact is expected to fall as the distance between the new grocery store and the residential property increases.

Given that the timeframe of our study, from 1988 to 2011, includes a dramatic increase in housing prices that occurred throughout Massachusetts during the middle of the timespan (Goodman et al. 2004), as well as the crash in the housing market associated with the Great Recession of 2008, both the level and time trend in prices are critical considerations in our application. While it does not appear that there is a great deal of difference between the overall time trend in housing prices for Worcester as a whole compared to the subgroup of housing sales within approximately one-half mile of all new grocery stores as can be seen in Figure 1, with further spatial disaggregation, the time trends can vary more greatly. Using a specific grocery store as an example, Figure 2 shows the time trend for all residential sales over the time period within 800 meters of this particular grocery store compared with residential sales within more disaggregated distances around the grocery store. There is more variability in housing prices at this particular scale in both the temporal and spatial dimensions. Therefore, similar to Pope and Pope (2015), we check the validity of our difference-in-differences results by exploring a set of falsification tests in which the opening year of grocery stores is shifted to earlier years.

\section{Data Description}

Housing sales data from the Warren Group were purchased for all residential sales that occurred in the city of Worcester over the period 1988 through 2011. These data include information on the location of the property, date of 

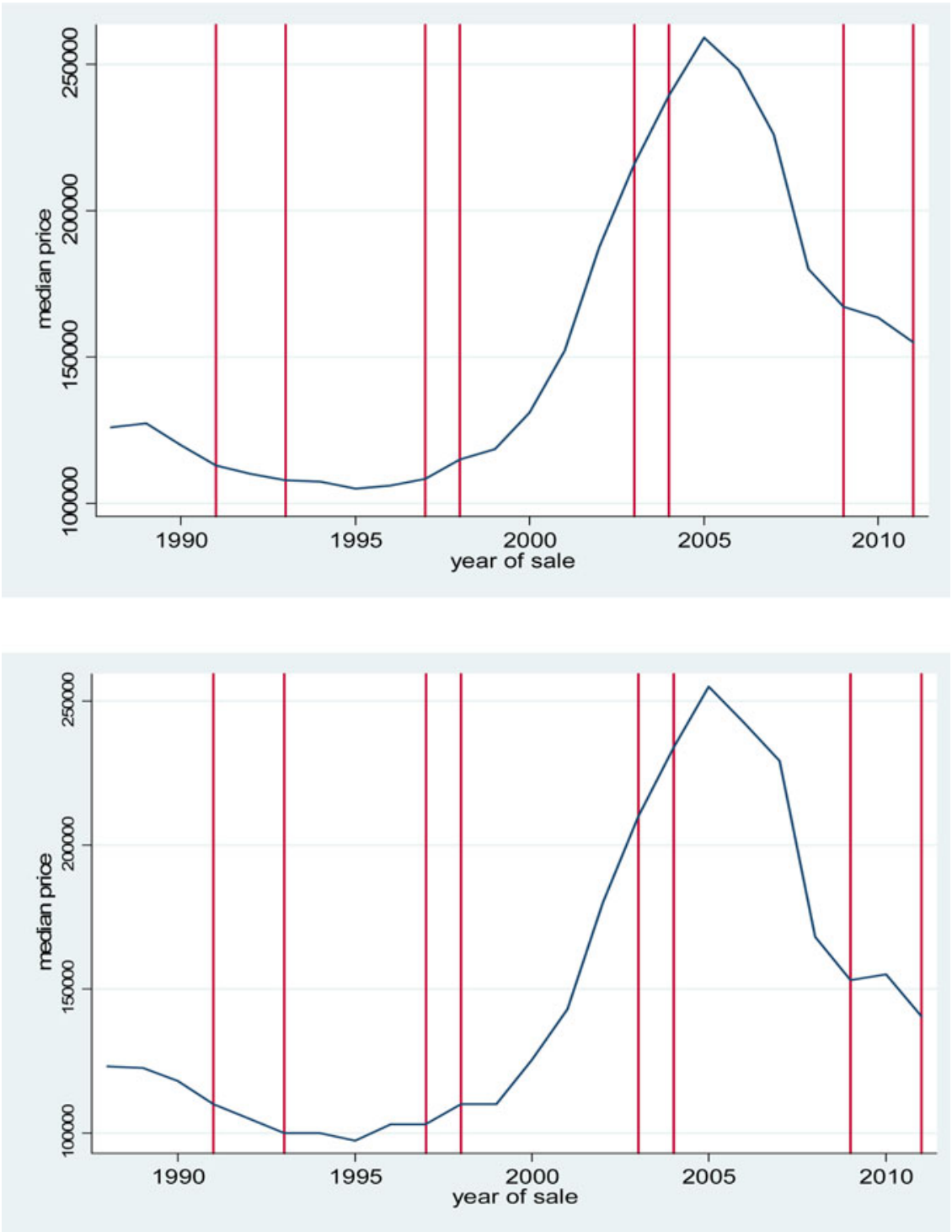

\section{Figure 1. Median Price of Houses.}

a) Includes all properties in the sample b) Includes properties located within half a mile from a grocery store.

sale, style of the structure, lot size, and other housing characteristics. Neighborhood characteristics are from the American Community Survey (ACS) 5-year summary (2006-2010). Data on grocery store location and year of opening were obtained from Reference USA (July 2012) for SIC code equal 

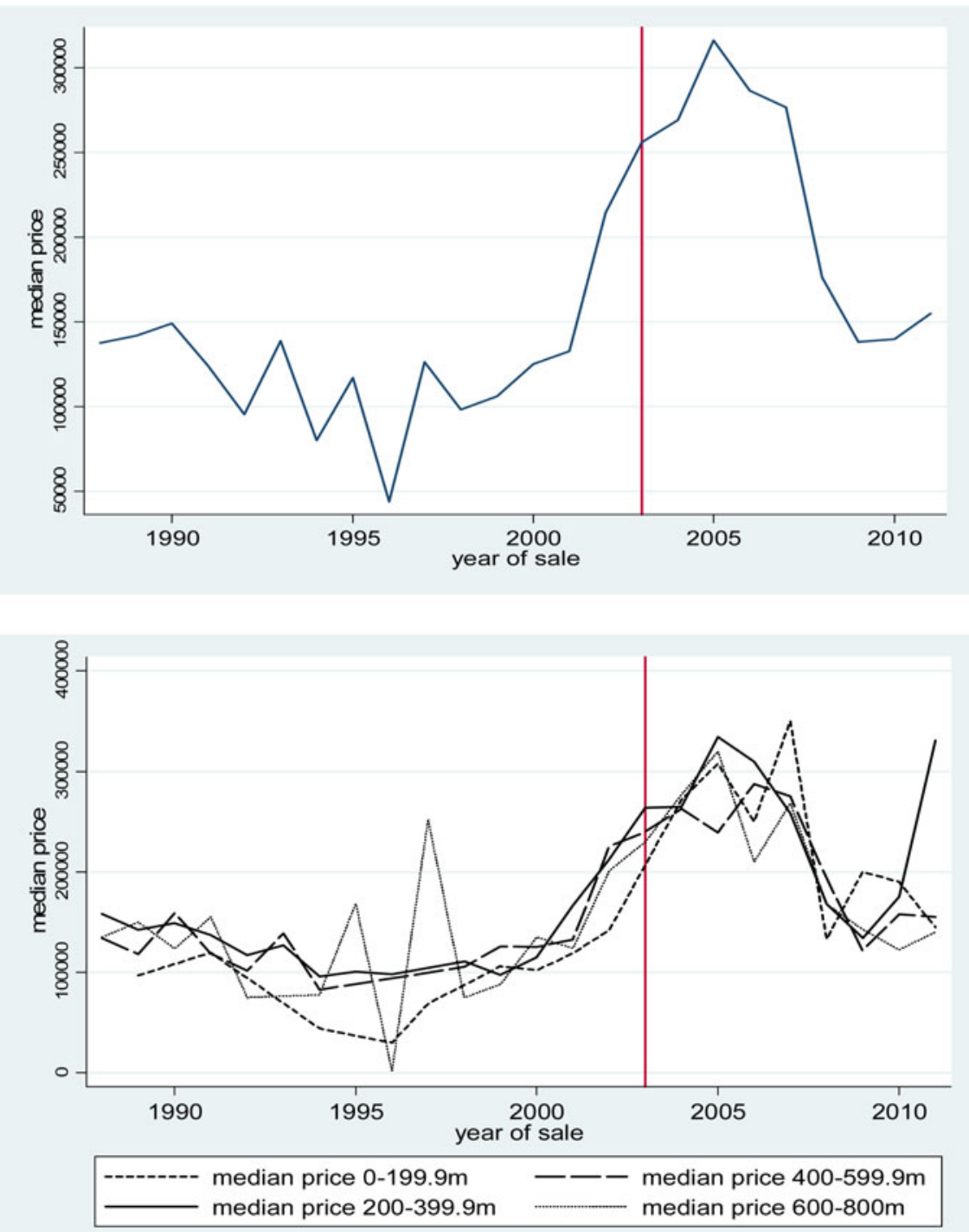

Figure 2. Average Price of Houses Located 0-800 Meters from Price Chopper Located at 50 Cambridge Street, Worcester MA.

a) Includes all properties 0-800 meters b) Separates properties by buffering zone

to 541105 and 531102. The first SIC code corresponds to grocers-retail businesses, and the latter is for supercenters that also sell food products, of which there was one in our sample, at the southern edge of the city (see Figure 3). Date of grocery store opening was confirmed through Worcester 


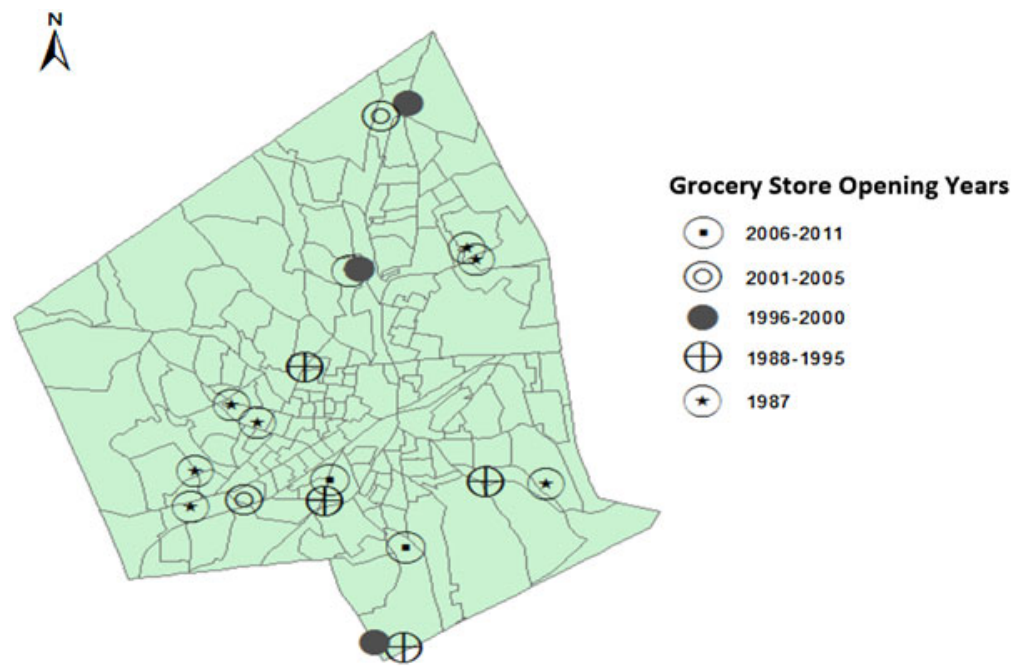

\section{Figure 3. Years of Grocery Stores Opening in Worcester.}

Note: Grocery stores opening on 1987 or before are labeled as "1987."

City's directories for assorted years (Polk 1988-2011). During our study period, twelve new grocery stores opened. The stores were at least 40,000 square feet in size and sold a wide variety of food products ranging from fresh vegetables and fruits to processed foods. Excluded from the data were smaller specialty stores, convenience stores, and retail bakeries. Figure 3 shows the evolution of grocery stores in Worcester during the study period.

All these data were geocoded for spatial analysis. Two mutually exclusive spatial buffers were created around each of the twelve new grocery stores (0-399.9 meters and 400-800 meters), representing the " $d$ " distances for the indicator variables discussed in equation 1 to determine the residential sales within each distance category. The summary statistics for the housing data, including sales price, and neighborhood characteristics can be found in Table 1 .

\section{Results and Discussion}

Our analysis follows the difference-in-differences approach presented in Equation 1. The regression includes spatial indicators to distinguish prices between residential sales properties located more than 800 meters from each new grocery store to properties located within 800 meters. The properties within the 800-meter distance were divided into two mutually exclusive rings which allow for a more detailed comparison between homes located close to a grocery store to those located further away. The estimated coefficients and standard errors of these spatial variables and their interactions with the 
Table 1. Summary Statistics of Housing Data

\begin{tabular}{|c|c|c|c|c|}
\hline & $\begin{array}{l}\text { All Residential } \\
\text { Properties }\end{array}$ & $\begin{array}{c}0-399.9 \\
\text { Meters }\end{array}$ & $\begin{array}{c}400-800 \\
\text { Meters }\end{array}$ & $\begin{array}{l}800 \text { Meters } \\
\text { or More }\end{array}$ \\
\hline $\begin{array}{l}\text { Price 1988-2011 } \\
\quad \text { (Average) }^{2}\end{array}$ & $\begin{array}{l}\$ 175,759.3 \\
(76,329.54)\end{array}$ & $\begin{array}{l}\$ 173,661.7 \\
(77234.4)\end{array}$ & $\begin{array}{l}\$ 171,136.9 \\
(75530.63)\end{array}$ & $\begin{array}{l}\$ 177,671 \\
(76461.58)\end{array}$ \\
\hline lot size (sq ft) & $\begin{array}{l}1542.93 \\
(5893.29)\end{array}$ & $\begin{array}{l}1166.54 \\
(3127.04)\end{array}$ & $\begin{array}{l}1373.8 \\
(4267.75)\end{array}$ & $\begin{array}{l}1641.18 \\
(6570.30)\end{array}$ \\
\hline Bathrooms & $\begin{array}{l}1.86 \\
(0.87)\end{array}$ & $\begin{array}{l}2.05 \\
(0.94)\end{array}$ & $\begin{array}{l}1.92 \\
(0.95)\end{array}$ & $\begin{array}{l}1.82 \\
(0.83)\end{array}$ \\
\hline Bedrooms & $\begin{array}{l}4.05 \\
(2.25)\end{array}$ & $\begin{array}{l}4.84 \\
(2.51)\end{array}$ & $\begin{array}{l}4.58 \\
(2.62)\end{array}$ & $\begin{array}{l}3.78 \\
(2.01)\end{array}$ \\
\hline Age & $\begin{array}{l}65.49 \\
(37.05)\end{array}$ & $\begin{array}{l}82.01 \\
(34.31)\end{array}$ & $\begin{array}{l}75.83 \\
(36.84)\end{array}$ & $\begin{array}{l}60.13 \\
(36.11)\end{array}$ \\
\hline $\begin{array}{l}\text { Annual median } \\
\text { household income } \\
(2010 \text { inflation- } \\
\text { adjusted \$) }\end{array}$ & $\begin{array}{l}\$ 58,196.42 \\
(25,373.01)\end{array}$ & $\begin{array}{l}\$ 44,492.96 \\
(15,694.31)\end{array}$ & $\begin{array}{l}\$ 49,115.13 \\
(18,382.09)\end{array}$ & $\begin{array}{l}\$ 62,020.17 \\
(26,702.95)\end{array}$ \\
\hline $\begin{array}{l}\% \text { of households that } \\
\text { own } 1 \text { or more cars }\end{array}$ & $\begin{array}{l}87.74 \\
(12.28)\end{array}$ & $\begin{array}{l}87.75 \\
(9.61)\end{array}$ & $\begin{array}{l}86.77 \\
(10.9)\end{array}$ & $\begin{array}{l}88.03 \\
(12.83)\end{array}$ \\
\hline$\%$ White & $\begin{array}{l}70.71 \\
(21.31)\end{array}$ & $\begin{array}{l}56.47 \\
(24.54)\end{array}$ & $\begin{array}{l}63.97 \\
(23.17)\end{array}$ & $\begin{array}{l}73.87 \\
(19.43)\end{array}$ \\
\hline $\begin{array}{l}\text { Population density } \\
\text { per square mile }\end{array}$ & $\begin{array}{l}6186.43 \\
(4825.95)\end{array}$ & $\begin{array}{l}7650.12 \\
(5236.47)\end{array}$ & $\begin{array}{l}7512.05 \\
(5324.29)\end{array}$ & $\begin{array}{l}5671.35 \\
(4525.45)\end{array}$ \\
\hline \# Property Sales & 33949 & 2211 & 8576 & 23162 \\
\hline
\end{tabular}

post-opening grocery store indicator are shown in Table 2. Column 1 includes all the properties in the sample, column 2 excludes properties that had a sales price in the top 1 percent of sales price observations, and column 3 excludes properties that had a price in the top 5 percent of sales price observations. Standard errors were clustered at the blockgroup level. The estimates of the coefficients of the spatial variables suggest that properties located within each of the two spatial buffers were associated with lower prices compared to properties located more than 800 meters away. Each of the indicator variables $D_{i j}^{0-399.9}$ and $D_{i j}^{400-800}$ has a negative and statistically significant coefficient indicating that properties located within 800 meters from a grocery store site sold at a price between 7 and 8 percent below the value of comparable properties located more than 800 meters away from the store.

2 This average excluded properties in the sample that had a sales price in the top 1 percent. 
Table 2. Impact of Grocery Store Openings in Housing Prices

\begin{tabular}{lccc}
\hline Sample & $\begin{array}{c}\text { All } \\
\text { Observations }\end{array}$ & $\begin{array}{c}\text { Excludes Properties } \\
\text { with Top 1\% Prices }\end{array}$ & $\begin{array}{c}\text { Excludes Properties } \\
\text { with Top 5\% Prices }\end{array}$ \\
\hline Variables & $\mathbf{( 1 )}$ & $\mathbf{( 2 )}$ & $\mathbf{( 3 )}$ \\
\hline logprice & logprice & logprice \\
Grocery store distance & $-0.076^{* * *}$ & $-0.073^{* * *}$ & $-0.072^{* * *}$ \\
0-399.9 meters & $(0.028)$ & $(0.027)$ & $(0.027)$ \\
Grocery store distance & $-0.081^{* * *}$ & $-0.080^{* * *}$ & $-0.076^{* * *}$ \\
400-800 meters & $(0.018)$ & $(0.018)$ & $(0.017)$ \\
Grocery store distance & $0.073^{* * *}$ & $0.070^{* * *}$ & $0.071^{* * *}$ \\
0-399.9 m*Post & $(0.024)$ & $(0.024)$ & $(0.024)$ \\
Grocery store & & & $0.037^{* *}$ \\
Grocery store distance & $0.039^{* *}$ & $0.039^{* *}$ & $(0.018)$ \\
400-800 m*Post & $(0.019)$ & $(0.019)$ & Yes \\
Grocery store & & & Yes \\
Housing Characteristics & Yes & Yes & Yes \\
Neighborhood & Yes & Yes & 32,619 \\
Characteristics & Yes & Yes & 0.584 \\
Clustered SE & 33,849 & 33,583 & \\
\hline N & 0.589 & 0.599 & \\
R-squared & & & \\
\hline
\end{tabular}

Robust standard errors in parentheses

*** $\mathrm{p}<0.01,{ }^{* *} \mathrm{p}<0.05,+\mathrm{p}<0.1$

Note: All regressions control for year fixed effects

Overall, this suggests that grocery stores are located in lower priced neighborhoods. The first row of Table 1 shows the average sales price of all the properties sold between 1988 and 2011. Average sales price for properties within the 800-meter buffers were below the city's average sales price and below the prices of properties located more than 800 meters away from a grocery store. This could reflect the differences in housing structure and neighborhood characteristics. Houses within the 800-meter buffers are on average older and have a smaller lot size, and these neighborhoods are more racially diverse and densely populated.

In terms of the impact of a new grocery store development on real estate prices, the estimated coefficient of the interaction term $D_{i j}^{d}$ Post $i y$ identifies the effect on sales price of a house located within a specific distance band from the grocery store. The estimated coefficients of $D_{i j}^{0-399.9}$ Post $i y$ and $D_{i j}^{400-800}{ }^{\text {Post }} t_{i y}$ have positive magnitudes. In addition, the coefficient is larger for properties located closest to the grocery store. For example, as shown in columns 1-3 of Table 2, properties located within 399.9 meters from a 
Table 3. Impact of Grocery Store Openings in Housing Prices for More Disaggregated Buffers

\begin{tabular}{|c|c|c|c|}
\hline Sample & $\begin{array}{c}\text { All } \\
\text { Observations }\end{array}$ & $\begin{array}{l}\text { Excludes Properties } \\
\text { with Top 1\% Prices }\end{array}$ & $\begin{array}{l}\text { Excludes Properties } \\
\text { with Top 5\% Prices }\end{array}$ \\
\hline & (1) & (2) & (3) \\
\hline Variables & logprice & logprice & logprice \\
\hline $\begin{array}{l}\text { Grocery store distance } \\
0-199.9 \text { meters }\end{array}$ & $\begin{array}{l}-0.10366 \\
(0.06349)\end{array}$ & $\begin{array}{c}-0.10062 \\
(0.06409)\end{array}$ & $\begin{array}{c}-0.09851 \\
(0.06452)\end{array}$ \\
\hline $\begin{array}{l}\text { Grocery store distance } \\
\text { 200-399.9 meters }\end{array}$ & $\begin{array}{c}-0.07078^{* *} \\
(0.02840)\end{array}$ & $\begin{array}{c}-0.06747^{* *} \\
(0.02844)\end{array}$ & $\begin{array}{c}-0.06674^{* *} \\
(0.02763)\end{array}$ \\
\hline $\begin{array}{l}\text { Grocery store distance } \\
\text { 400-599.9 meters }\end{array}$ & $\begin{array}{c}-0.0749 * * * \\
(0.02149)\end{array}$ & $\begin{array}{c}-0.0705^{* * *} \\
(0.02099)\end{array}$ & $\begin{array}{c}-0.0713^{* * *} \\
(0.02115)\end{array}$ \\
\hline $\begin{array}{l}\text { Grocery store distance } \\
600-800 \text { meters }\end{array}$ & $\begin{array}{c}-0.0845^{* * *} \\
(0.02107)\end{array}$ & $\begin{array}{c}-0.0845^{* * *} \\
(0.02056)\end{array}$ & $\begin{array}{c}-0.0788^{* * *} \\
(0.02026)\end{array}$ \\
\hline $\begin{array}{l}\text { Grocery store distance } \\
0-199.9 \text { m*Post } \\
\text { Grocery store }\end{array}$ & $\begin{array}{c}0.09786+ \\
(0.05840)\end{array}$ & $\begin{array}{c}0.09685 \\
(0.05965)\end{array}$ & $\begin{array}{c}0.09464 \\
(0.05956)\end{array}$ \\
\hline $\begin{array}{l}\text { Grocery store distance } \\
\text { 200-399.9 m*Post } \\
\text { Grocery store }\end{array}$ & $\begin{array}{l}0.06805^{* *} \\
(0.02634)\end{array}$ & $\begin{array}{l}0.06516^{* *} \\
(0.02617)\end{array}$ & $\begin{array}{l}0.06703^{* *} \\
(0.02598)\end{array}$ \\
\hline $\begin{array}{l}\text { Grocery store distance } \\
\text { 400-599.9 m*Post } \\
\text { Grocery store }\end{array}$ & $\begin{array}{c}0.01695 \\
(0.02448)\end{array}$ & $\begin{array}{c}0.01561 \\
(0.02377)\end{array}$ & $\begin{array}{c}0.01632 \\
(0.02409)\end{array}$ \\
\hline $\begin{array}{l}\text { Grocery store distance } \\
\text { 600-800 m*Post } \\
\text { Grocery store }\end{array}$ & $\begin{array}{l}0.05274^{* *} \\
(0.02271)\end{array}$ & $\begin{array}{l}0.05241^{* *} \\
(0.02231)\end{array}$ & $\begin{array}{l}0.04979^{* *} \\
(0.02200)\end{array}$ \\
\hline Housing Characteristics & Yes & Yes & Yes \\
\hline $\begin{array}{l}\text { Neighborhood } \\
\text { Characteristics }\end{array}$ & Yes & Yes & Yes \\
\hline Clustered SE & Yes & Yes & Yes \\
\hline $\mathrm{N}$ & 33,849 & 33,583 & 32,619 \\
\hline R-squared & 0.58925 & 0.59944 & 0.58413 \\
\hline
\end{tabular}

Robust standard errors in parentheses

*** $\mathrm{p}<0.01,{ }^{* *} \mathrm{p}<0.05,+\mathrm{p}<0.1$

Note: All regressions control for year fixed effects

grocery store experienced a 7 percent increase in price after the store opened, while properties located within 400-800 meters from the grocery store experienced approximately a 4 percent increase in value. As a comparison, Pope and Pope (2015) found that a new Walmart store increases housing prices between 2 and 3 percent for houses located within 0.5 miles of the 
Table 4. Falsification Tests of Grocery Store Opening Year and Impact on Housing Prices

\begin{tabular}{lccc}
\hline $\begin{array}{l}\text { Number of Years Grocery Store Opening } \\
\text { Date is Shifted }\end{array}$ & $\begin{array}{c}\text { 3 years } \\
\text { earlier }\end{array}$ & $\begin{array}{c}\text { 4 years } \\
\text { earlier }\end{array}$ & $\begin{array}{c}\mathbf{5} \text { years } \\
\text { earlier }\end{array}$ \\
\hline Variables & $\mathbf{( 1 )}$ & $\mathbf{( 2 )}$ & $\mathbf{( 3 )}$ \\
\hline logprice & logprice & Logprice \\
\hline Grocery store distance 0-399.9 meters & $-0.124^{* * *}$ & $-0.121^{* *}$ & $-0.111^{* *}$ \\
Grocery store distance 400-800 meters & $(0.030)$ & $(0.034)$ & $(0.035)$ \\
& $-0.097^{* * *}$ & $-0.102^{* * *}$ & $-0.103^{* * *}$ \\
Grocery store distance 0-399.9 m*Post & $(0.019)$ & $(0.020)$ & $(0.021)$ \\
$\quad$ Grocery store & 0.044 & 0.036 & 0.020 \\
Grocery store distance 400-800 m*Post & $(0.031)$ & $(0.037)$ & $(0.040)$ \\
Grocery store & 0.018 & 0.024 & 0.024 \\
\hline Housing Characteristics & $(0.016)$ & $(0.017)$ & $(0.018)$ \\
Neighborhood Characteristics & Yes & Yes & Yes \\
Clustered SE & Yes & Yes & Yes \\
\hline R-squared & Yes & Yes & Yes \\
N & 0.592 & 0.592 & 0.592 \\
\hline
\end{tabular}

Robust standard errors in parentheses

*** $\mathrm{p}<0.01,{ }^{* *} \mathrm{p}<0.05,+\mathrm{p}<0.1$

Note: All regressions control for year fixed effects

store, while similar positive results for a new Walmart within a two-mile radius of a residential prices can be found in Johnson et al. (2015).

The estimated coefficients on the control variables have the expected signs and are statistically significant: homes with more bedrooms and bathrooms sell at a higher price, as do properties with larger lots. Homes in neighborhoods with lower income, lower education levels and higher percentages of minorities sell at lower prices.

In order to test the robustness of these results, we further disaggregated the 800-meter distance into four mutually exclusive rings (0-199.9 meters, 200399.9 meters, 400-599.9 meters, and 600-800 meters) centered around each of the grocery stores. One of our hypotheses was that a new grocery store would have a nonmonotonic effect on neighboring housing prices, where properties in close proximity to a grocery store experienced a negative impact, and properties located further away experienced a positive distance-decaying effect. However, as shown in Table 3, this relation was not observed across the coefficients of the interaction terms. In fact, the coefficients of the interaction terms $D_{i j}^{0-199.9}{ }^{\text {Post }}{ }_{i y}$ and $D_{i j}^{400-599.9}{ }^{\text {Post }}{ }_{i y}$ are not statistically significant. 
Finally, falsification tests were conducted to identify whether the observed increase in housing prices was due to a grocery store opening a short distance from the property. One of the concerns is that there may be confounding factors affecting the price of houses close to the grocery store's site before its announcement and opening date. Hence, similar to Pope and Pope (2015), we constructed false opening dates for the grocery stores and shifted the opening years of grocery stores three, four, and five years prior to the actual opening years ${ }^{3}$. If the grocery store had an impact on property values, we should observe a positive effect when the grocery store is announced and opened, and not in prior years. The results of these tests are shown in Table 4. None of the coefficients of the interaction terms provide evidence of property values near a grocery store's site increasing in value three, four, and five years before the store's actual opening year. Thus, these results suggest that the opening of a new grocery store does have a positive effect on nearby residential property values.

\section{Conclusions}

In this study, we investigated the effect of the opening of a new grocery store on housing prices in Worcester, Massachusetts for the period 1988-2011. Using geocoded housing sales data of single-family homes, different mutually exclusive neighborhoods were created around each new store opening. A hedonic model with a difference-in-differences econometric specification was developed to test the impact of the opening of each new grocery stores on its neighboring property values. Our results indicate that properties located between 400-800 meters and 0-399.9 meters from a grocery store experienced between 4 and 7 percent increase, respectively, in the level of prices relative to similar properties located across the city and more than 800 meters away from a grocery store.

Our results also suggest that grocery stores in Worcester were in lower property-valued neighborhoods. In particular, our results suggest that prices of properties located within 800 meters from a grocery store were between 7 and 8 percent below the value of properties located more than 800 meters away. Although our analysis does not incorporate an empirical analysis specific to food desert areas due to data limitations, many of the grocery stores were established in the city's low-income census blockgroups. In fact, most grocery stores were in neighborhoods where household income was below the city's average median income and where minorities made up a

\footnotetext{
3 Pope and Pope (2015) found that the average Walmart in their sample took about 1.5 years to be built after its construction and opening were announced. As our dataset includes only the year in which the grocery store opened, we shifted the grocery store opening by three, four, and five years. This allowed us to reduce possible changes in housing prices due to announcement rather than the opening of the grocery store.
} 
larger percentage of the population. Therefore, in addition to the potential health benefits of increased access to healthy food for these lower-income residents, there are these additional potential benefits, such as job creation and community development, as well as the specific benefits that are the focus of this study: the wealth impacts for these residents via the increase in housing values. Thus, given the government's current interest in the relocation and expansion of grocery stores in low-income neighborhoods, the analysis and discussion provided in this paper could help inform policymakers about some of the economic impact that policies seeking to expand grocery stores in lower-income areas may generate.

\section{References}

Auld, C., and L.M. Powell. 2008. "Economics of Food Energy Density and Adolescent Body Weight." Economica 76(304): 719-740.

Bowes, D.R. and K.R. Ihlanfeldt. 2001. "Identifying the Impacts of Rail Transit Stations on Residential Property Values." Journal of Urban Economics 50(1): 1-25.

Brown, A.F., R.B. Vargas, A. Ang, and A.R. Pebley. 2008. "The Neighborhood Food Resource Environment and the Health of Residents with Chronic Conditions." Journal of General Internal Medicine 23(8): 1137-1144.

Brown, J. and J. Geoghegan. 2011. "Spatially Delineated Public Goods and Spatially Located Public Bads: A Hedonic Approach to Measuring Urban Revitalization." Agricultural and Resource Economics 40(3): 360-374.

Chen, S., R.J.G.M. Florax, S. Snyder, and C.C. Miller. 2010. "Obesity and Access to Chain Grocers." Economic Geography 86(4): 431-452.

Cummins, S., E. Flint and S.A. Matthews. 2014. "New Neighborhood Grocery Store Increased Awareness of Food Access but did not Alter Dietary Habits or Obesity." Health Affairs 33 (2): 283-291.

Ellickson, P. B. and P.L.E. Grieco. 2013. "Wal-Mart and the Geography of Grocery Retailing." Journal of Urban Economics 75(1): 1-14.

Executive Office of Economic Development, City of Worcester MA. 2012. Final Report: Housing Market Study, City of Worcester, Massachusetts. Worcester MA. Available at: http://www.worcesterma.gov/uploads/f2/ef/f2ef28431a277dae311f2906bf85fb9c/ housing-strategy-study.pdf

Flegal, K.M., M.D. Carroll, B.K. Kit, and C.L. Ogden. 2012. "Prevalence of Obesity and Trends in the Distribution of Body Mass Index among US Adults, 1999-2010." The Journal of the American Medical Association 307(5): 491-497.

Galster, G., K. Temkin, C. Walker, and N. Sawyer. 2004. "Measuring the Impacts of Community Development Initiatives A New Application of the Adjusted Interrupted Time-Series Method." Evaluation Review 28(6): 502-538.

Galvez, M.P., L. Hong, E. Choi, L. Liao, J. Godbold, and B. Brenner. 2009. "Childhood Obesity and Neighborhood Food-Store Availability in an Inner-City Community." Academic Pediatrics 9(5): 339-343.

Geoghegan, J. 2002. "The Value of Open Spaces in Residential Land Use." Land Use Policy 19(1): 91-98.

Goodman, M.D., J. Palma, L. Kipshidze, R. Lacey, R. Loveland, and A. Proshina, 2004. "Winners and Losers in the Massachusetts Housing Market." A Study for Citizens' Housing and Planning Association and the Massachusetts Housing Partnership. Healthy Food Access Portal. "Policy Efforts and Impacts." Available at http://www.healthyfoodaccess.org/ policy-efforts-and-impacts/federal. 
Holzman, D.C. 2010. "Diet and Nutrition: White House Proposed Health Food Financing Initiative." Environmental Health Perspectives 118(4): A156.

Johnson, D., K.M. Lybecker, N. Gurley, A. Stiller-Shulman, and S. Fischer. 2015. "The NWIMBY Effect (No WalMart In My BackYard): Big Box Stores and Residential Property Values." Proceedings of Business and Social Sciences Research Conference, Bangkok, Thailand.

Kiel, K.A. and M. Williams. 2007. "The Impact of Superfund sites on Local Property Values: Are all Sites the Same?" Journal of Urban Economics 61(1): 170-192.

Krukowski, R.A., D.S. West, J. Harvey-Berino, and E.T. Prewitt. 2010. "Neighborhood Impact on Healthy Food Availability and Pricing in Food Stores." Journal of Community Health 35(3): 315-320.

Leggett, C.G. and N.E. Bockstael. 2000. "Evidence on the Effects of Water Quality on Residential Land Prices." Journal of Environmental Economics and Management 39(2): 121-144.

Manon, M. and J. Tucker. 2012. "Simulating Grocery Development in Massachusetts: A Report of the Massachusetts Grocery Access Task Force." Philadelphia, PA: The Food Trust. 18 pps.

Morland, K., S. Wing, and A. Diez Roux. 2002. "The Contextual Effect of the Local Food Environment on Residents' Diets: The Atherosclerosis Risk in Communities Study." Journal Information 92(11): 1761-1768.

Nguyen, D.M. and H.B. El-Serag. 2010. "The Epidemiology of Obesity." Gastroenterology Clinics of North America 39(1): 1-7.

Palmquist, R.B. 2005. "Property Value Models.” Handbook of Environmental Economics 2: 763-819.

Parmeter, C.F., and J.C. Pope. 2013. "Quasi-Experiments and Hedonic Property Value Methods." in Handbook on Experimental Economics and the Environment Eds. J.A. List and M.K. Price, Northhampton, MA: Edward Elgar Publishing.

Polk, R.L. 1993. South Worcester County Massachusetts City Directory: Including Dudley, Oxford, Southbridge, Sturbridge and Webster. Richmond, VA: R.L. Polk \& Co.

Pope, J.C. 2008. "Buyer Information and the Hedonic: The Impact of Seller Disclosure on the Implicit Price for Airport Noise." Journal of Urban Economics 63(2): 498-516.

Pope, D.G. and J.C. Pope. 2015. "When Walmart comes to Town: Always Low Housing Prices? Always?" Journal of Urban Economics 87(May): 1-13.

Powell, L.M., S. Slater, D. Mirtcheva, Y. Bao, and F.J. Chaloupka. 2007. "Food Store Availability and Neighborhood Characteristics in the United States." Preventive Medicine, 44(3): 189-195.

Smith, V.K., and J.C. Huang. 1993. "Hedonic Models and Air Pollution: Twenty-Five Years and Counting." Environmental and Resource Economics 3: 381-394.

The White House Office of the First Lady. 2011. "First Lady Michele Obama Announces Nationwide Commitments to Provide Millions of People Access to Healthy, Affordable Food in Underserved Communities." Available at https://www.whitehouse.gov/thepress-office/2011/07/20/first-lady-michelle-obama-announces-nationwide-commitmentsprovide-milli

U.S. Department of Agriculture. 2014. "2014 Farm Bill Highlights". Available at http://www. usda.gov/documents/usda-2014-farm-bill-highlights.pdf

Economic Research Service. 2009. "Access to Affordable and Nutritious Food: Measuring and Understanding Food Deserts and Their Consequences, Report to Congress." ERS, U.S. Department of Agriculture, Washington, D.C. Available at http://www.ers.usda.gov/ Publications/AP/AP036/

Walker, R.E., C.R. Keane, and J.G. Burke. 2010. "Disparities and Access to Healthy Food in the United States: A Review of Food Deserts Literature." Health and Place 16(5): 876-884. 
Wang, Y., and M.A. Beydoun. 2007. "The Obesity Epidemic in the Unites States - Gender, Age, Socioeconomics, Racial/Ethnic, and Geographic Characteristics: A Systematic Review and Meta-Regression Analysis." Epidemiological Reviews 29(1): 6-28.

Yan, R., N.D. Bastian, and P.M. Griffin. 2015. "Association of Food Environment and Food Retailers with Obesity in U.S. Adults." Health and Place 33: 19-24.

Zenk, S.N., A.J. Schulz, B.A. Israel, S.A. James, S. Bao, and M.L. Wilson. 2005. "Neighborhood Racial Composition, Neighborhood Poverty, and the Spatial Accessibility of Supermarkets in Metropolitan Detroit." Journal Information 95(4): 660-667. 